\title{
Rectal Cancer: Its Causes and Risk Factors in the Society as Related to Nigeria
}

\author{
Article by Akanji Christianah Abimbola \\ $R N-M S N$, Texila American University, Nigeria \\ E-mail: cakanji@texilaconnect.com
}

\begin{abstract}
Rectal cancer is a disease in which malignant (cancer) cells form in the tissues of the rectum. Age and family history can affect the risk of rectal cancer. Signs of rectal cancer include a change in bowel habits or blood in the stool. Rectal bleeding is a symptom of a problem in the GI (Gastrointestinal tract). The definition is broad as it means any blood passed rectally; consequently, the blood may come from any area or structure in the GI tract that allows blood to leak into the GI lumen (area where food and fluid is processed for absorption or removal as waste). For example, a bleeding ulcer in the stomach can have the blood excreted in the person's fecal material Rectal bleeding may be due to problems on the rectum itself or from many other problems that occur elsewhere in the GI tract. Perirectal bleeding is bleeding in an area adjacent to the rectum and may be due to abscesses or fistulas.

Rectal cancer is the growth of abnormal cancerous cells in the lower part of the colon that connects the anus to the large bowel. Rectal cancer develops usually over years; its actual cause is not known, but risk factors include increasing age (over 50), smoking, family history, high-fat diet, or a history of polyps or colorectal cancer or inflammatory bowel disease.

Radiation therapy can be used to kill or shrink rectal cancers. Follow-up is important to make sure that rectal cancer does not recur.
\end{abstract}

\section{Introduction}

The rectum is part of the body's digestive system. The digestive system takes in nutrients (vitamins, minerals, carbohydrates, fats, proteins, and water) from foods and helps pass waste material out of the body. The digestive system is made up of the oesophagus, stomach, and the small and large intestines. The colon (large bowel) is the first part of the large intestine and is about 5 feet long. Together, the rectum and anal canal make up the last part of the large intestine and are 6-8 inches long. The anal canal ends at the anus (the opening of the large intestine to the outside of the body). Tests that examine the rectum and colon are used to detect (find) and diagnose rectal cancer. Certain factors affect prognosis (chance of recovery) and treatment options.

Medical treatment depends on the stage of rectal cancer. The most severe stage; multiple chemotherapy medications are available and are chosen by the specialist (oncologist) to fit the individual's stage of rectal cancer.

Rectal cancer is a disease in which malignant (cancer) cells form in the tissues of the rectum. Age and family history can affect the risk of rectal cancer. Signs of rectal cancer include a change in bowel habits or blood in the stool. Tests that examine the rectum and colon are used to detect (find) and diagnose rectal cancer. Certain factors affect prognosis (chance of recovery) and treatment options.

The outlook or prognosis for individuals with rectal cancer is usually related to the stage of cancer, with stages III and IV having the poorest outcomes.

Histologically, adenomas are classified in three groups: tubular, tubulovillous, and villous adenomas. K-ras mutations and microsatellite instability have been identified in hyperplastic polyps. Therefore, hyperplastic polyps may also have malignant potential in varying degrees.

The other common carcinogenic pathway involves mutation in DNA mismatch repair genes. Many of these mismatched repair genes have been identified, including $h M L H 1, h M S H 2, h P M S 1, h P M S 2$, and $h M S H 6$. Mutation in mismatched repair genes negatively affects the DNA repair. This replication error is found in approximately $90 \%$ of HNPCC and $15 \%$ of sporadic colon and rectal cancers. A separate carcinogenic pathway is also described in inflammatory bowel disease (IBD). Chronic 
inflammation such as in ulcerative colitis can result in genetic alterations which then lead into dysplasia and carcinoma formation.

\section{Aim of the study}

The aim of this proposed study is not to replicate any of the initial work already conducted, but to emphasis on the causes of rectal cancer and the risk factors. This study is to determine the rapid growth of Rectal Cancer. Age and family history can affect the risk of rectal cancer, hence anything that increases your chance of getting a disease is called a risk factor. Rectal cancer develops usually over years; its actual cause is not known, but risk factors include increasing age (over 50), smoking, family history, high-fat diet, or a history of polyps or colorectal cancer or inflammatory bowel disease.

The major symptom of rectal cancer is bleeding from the rectum; other symptoms include anaemia, fatigue, shortness of breath, dizziness and/or a fast heartbeat, bowel obstruction, small diameter stools, and weight loss.

For diagnosis, exams and tests may include fecal occult blood testing, endoscopy, digital rectal examination, sigmoidoscopy, CT/MRI imaging studies, along with routine blood tests and detection of carcinoembryonic antigen (CEA).

Surgery is used to both treat and reduce symptoms and, in some individuals, may result in a remission of the cancer.

\section{Background to the study}

Rectal cancer incidence was negligible before 1900. The incidence of rectal cancer has been rising dramatically following economic development and industrialization. Currently, colorectal cancer is the third leading cause of cancer deaths in both males and females in the United States.

Adenocarcinomas comprise the vast majority (98\%) of colon and rectal cancers. Other rare rectal cancers, including carcinoid (0.4\%), lymphoma (1.3\%), and sarcoma $(0.3 \%)$, are not discussed in this article. Squamous cell carcinomas may develop in the transition area from the rectum to the anal verge and are considered anal carcinomas. Very rare cases of squamous cell carcinoma of the rectum have been reported.

Approximately $20 \%$ of colon cancers develop in the cecum, another $20 \%$ in the rectum, and an additional $10 \%$ in the rectosigmoid junction. Approximately $25 \%$ of colon cancers develop in the sigmoid colon.

The incidence and epidemiology, etiology, pathogenesis, and screening recommendations are common to both colon cancer and rectal cancer. These areas are addressed together.

An image depicting the staging and workup of rectal cancer can be seen below. 


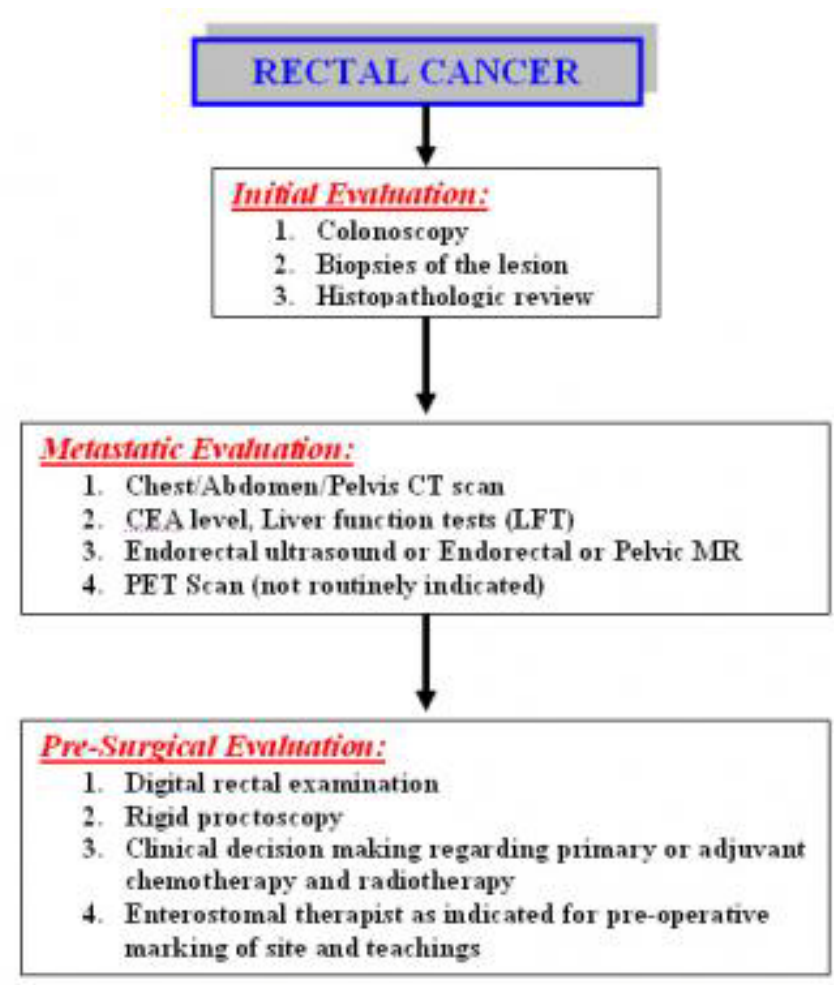

Diagnostics. Staging and workup of rectal cancer patients.

\section{Pathophysiology}

The mucosa in the large intestine regenerates approximately every 6 days. Crypt cells migrate from the base of the crypt to the surface, where they undergo differentiation and maturation, and ultimately lose the ability to replicate.

The significant portions of colorectal carcinomas are adenocarcinomas. The adenoma-carcinoma sequence is well described in the medical literature. Colonic adenomas precede adenocarcinomas. Approximately $10 \%$ of adenomas will eventually develop into adenocarcinomas. This process may take up to 10 years.

Three pathways to colon and rectal carcinoma have been described:

- Adenomatous polyposis coli (APC) gene adenoma-carcinoma pathway

- Hereditary nonpolyposis colorectal cancer (HNPCC) pathway

- Ulcerative colitis dysplasia

The APC adenoma carcinoma pathway involves several genetic mutations, starting with inactivation of the APC gene, which allows unchecked cellular replication at the crypt surface. With the increase in cell division, further mutations occur, resulting in activation of the K-ras oncogene in the early stages and mutations in later stages. These cumulative losses in tumor suppressor gene function prevent apoptosis and prolong the cell's lifespan indefinitely. If the APC mutation is inherited, it will result in familial adenomatous polyposis syndrome.

The HNPCC which involves the Age and family history can affect the risk of rectal cancer. Anything that increases your chance of getting a disease is called a risk factor. Having a risk factor does not mean that you will get cancer; not having risk factors doesn't mean that you will not get cancer. Medical consultation will be of help if you think you may be at risk.

\section{Rectal cancer symptoms}

In the early stages of the disease, rectal cancer symptoms may be minimal, or not present at all. As the disease progresses, symptoms may increase in quantity and degree of severity. Because colorectal cancer symptoms often do not present themselves until the disease has progressed past the initial stage, Signs of rectal cancer include a change in bowel habits or blood in the stool. These and other 
signs and symptoms may be caused by rectal cancer or by other conditions. The following symptoms might be present in patient with rectal cancer;

- Blood (either bright red or very dark) in the stool.

- A change in bowel habits.

- Diarrhea.

- Constipation.

- Feeling that the bowel does not empty completely.

- Stools that are narrower or have a different shape than usual.

- General abdominal discomfort (frequent gas pains, bloating, fullness, or cramps).

- Change in appetite.

- Weight loss for no known reason

- Feeling very tired.

Bleeding is the most common symptom of rectal cancer, occurring in $60 \%$ of patients. However, many rectal cancers produce no symptoms and are discovered during digital or proctoscopic screening examinations.

Other signs and symptoms of rectal cancer may include the following:

- Change in bowel habits (43\%): Often in the form of diarrhea; the caliber of the stool may change; there may be a feeling of incomplete evacuation and tenesmus

- Occult bleeding (26\%): Detected via a fecal occult blood test (FOBT)

- Abdominal pain (20\%): May be colicky and accompanied by bloating

- Back pain: Usually a late sign caused by a tumor invading or compressing nerve trunks

- Urinary symptoms: May occur if a tumor invades or compresses the bladder or prostate

- Malaise (9\%)

- Pelvic pain (5\%): Late symptom, usually indicating nerve trunk involvement

- Emergencies such as peritonitis from perforation (3\%) or jaundice, which may occur with liver metastases $(<1 \%)$

\section{Malignant (Cancer) cells formed in the tissues of the rectum}

The rectum is part of the body's digestive system. The digestive system takes in nutrients (vitamins, minerals, carbohydrates, fats, proteins, and water) from foods and helps pass waste material out of the body. The digestive system is made up of the esophagus, stomach, and the small and large intestines. The colon (large bowel) is the first part of the large intestine and is about 5 feet long. Together, the rectum and anal canal make up the last part of the large intestine and are 6-8 inches long. The anal canal ends at the anus (the opening of the large intestine to the outside of the body). 


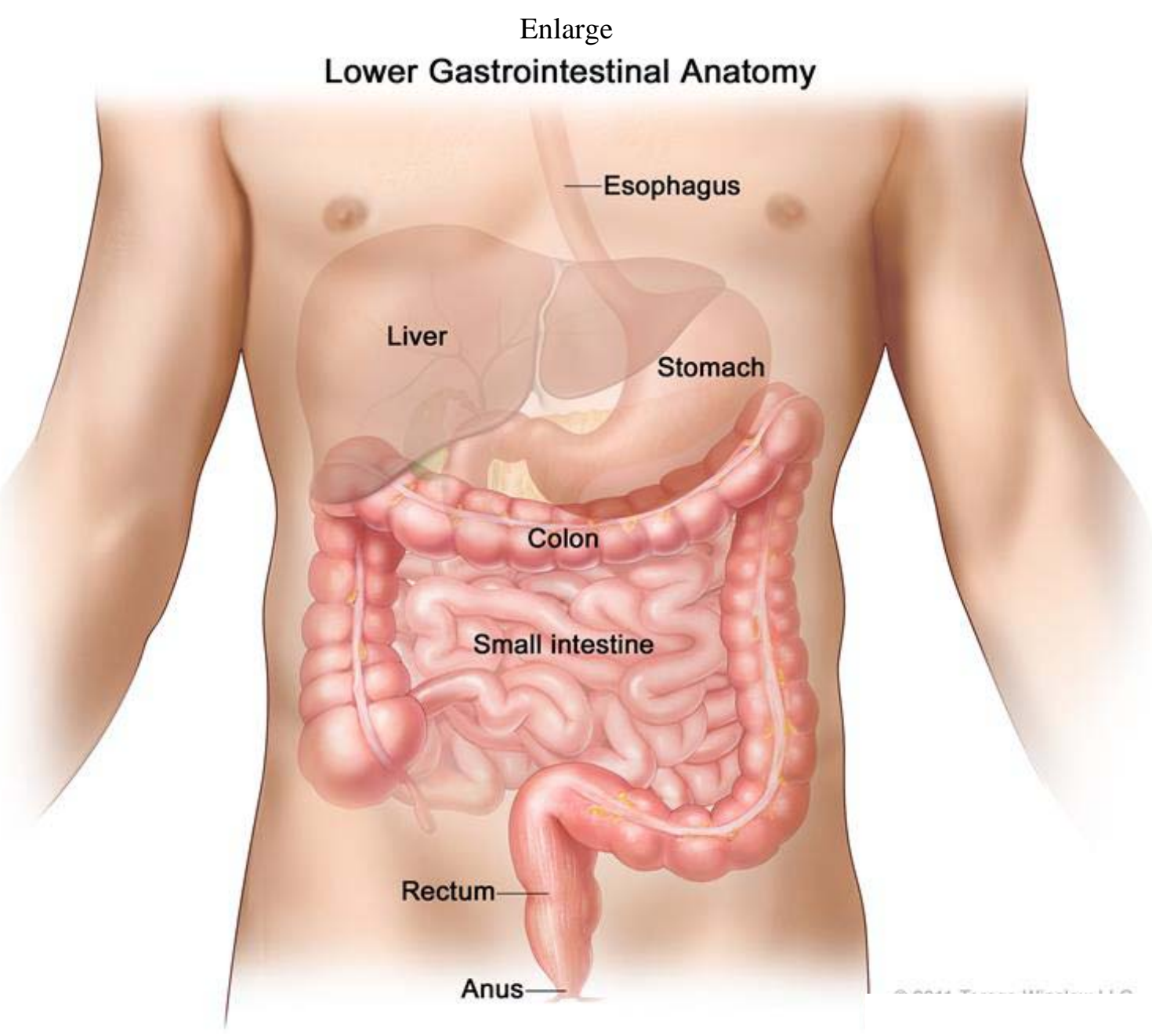

Anatomy of the lower digestive system, showing the colon and other organs.

See the following PDQ summaries for more information about rectal cancer:

- $\quad$ Unusual Cancers of Childhood Treatment (see Colorectal Cancer section)

- Colorectal Cancer Prevention

- $\quad$ Colorectal Cancer Screening

- Gastrointestinal Stromal Tumors Treatment

- Genetics of Colorectal Cancer

\section{Age and family history can affect the risk of rectal cancer}

Anything that increases your chance of getting a disease is called a risk factor. Having a risk factor does not mean that you will get cancer; not having risk factors doesn't mean that you will not get cancer. Talk with your doctor if you think you may be at risk. The following are possible risk factors for rectal cancer:

- Being aged 50 or older.

- Having certain hereditary conditions, such as familial adenomatous polyposis (FAP) and hereditary nonpolyposis colon cancer (HNPCC or Lynch syndrome).

- Having a personal history of any of the following:

- Colorectal cancer.

- Polyps (small pieces of bulging tissue) in the colon or rectum.

- Cancer of the ovary, endometrium, or breast.

Having a parent, brother, sister, or child with a history of colorectal cancer or polyps. 
Texila International Journal of Clinical Research

Volume 4, Issue 1, Dec 2016

\section{Tests used to diagnose rectal cancer}

- $\quad$ Physical exam and history : An exam of the body to check general signs of health, including checking for signs of disease, such as lumps or anything else that seems unusual. A history of the patient's health habits and past illnesses and treatments will also be taken.

- Digital rectal exam (DRE): An exam of the rectum. The doctor or nurse inserts a lubricated, gloved finger into the lower part of the rectum to feel for lumps or anything else that seems unusual. In women, the vagina may also be examined.

Colonoscopy : A procedure to look inside the rectum and colon for polyps (small pieces of bulging tissue), abnormal areas, or cancer. A colonoscope is a thin, tube-like instrument with a light and a lens for viewing. It may also have a tool to remove polyps or tissue samples, which are checked under a microscope for signs of cancerEnlarge

\section{Diagnosis}

Perform physical examination with specific attention to the size and location of the rectal tumor in addition to possible metastatic lesions, including enlarged lymph nodes or hepatomegaly. In addition, evaluate the remainder of the colon.

Examination includes the use of the following:

- Digital rectal examination (DRE): The average finger can reach approximately $8 \mathrm{~cm}$ above the dentate line; rectal tumors can be assessed for size, ulceration, and presence of any pararectal lymph nodes, as well as fixation to surrounding structures (eg, sphincters, prostate, vagina, coccyx and sacrum); sphincter function can be assessed

- Rigid proctoscopy: This examination helps to identify the exact location of the tumor in relation to the sphincter mechanism

\section{Laboratory tests}

Routine laboratory studies in patients with suspected rectal cancer include the following:

- Complete blood count

- Serum chemistries

- Liver and renal function tests

- Carcinoembryonic antigen (CEA) test

- Cancer antigen (CA) 19-9 assay, if available: May be useful for monitoring the disease

- Histologic examination of tissue specimens

- Screening tests may include the following:

- Guaiac-based FOBT

- $\quad$ Stool DNA screening (SDNA)

- Fecal immunochemical test (FIT)

- Rigid proctoscopy

- Flexible sigmoidoscopy (FSIG)

- Combined glucose-based FOBT and flexible sigmoidoscopy

- Double-contrast barium enema (DCBE)

- Computed tomography (CT) colonography

- Fiberoptic flexible colonoscopy (FFC)

\section{Rectal cancer diagnostics and treatment}

Rectal cancer experts use state-of-the-art diagnostic tools, including advanced imaging and laboratory tests, to evaluate rectal cancer. This diagnostic evaluation takes about three to five days. Then together, we develop a comprehensive rectal cancer treatment plan that works for individual. Your individualized plan will include advanced medical treatments and technologies, combined with integrative oncology services to help reduce side effects and keep you strong in body, mind and spirit. Surgery can also be used to both treat and reduce symptoms and, in some individuals, may result in a remission of the cancer. While Radiation therapy is also used to kill or shrink rectal cancers. 


\section{Survival results: rectal cancer}

Information regarding the survival results of patients with distant (also referred to as metastatic) rectal cancer who were diagnosed and/or at least initially partly treated to help patient decide where to go for treatment, as part of many other factors that may be considering. Therefore, asked an independent biostatistician to analyze the survival results of rectal cancer patients.

The chart below shows the cancer survival rates for a group of 362 metastatic rectal cancer patients who were diagnosed between 2000 and 2011. Each patient in the group was first diagnosed.

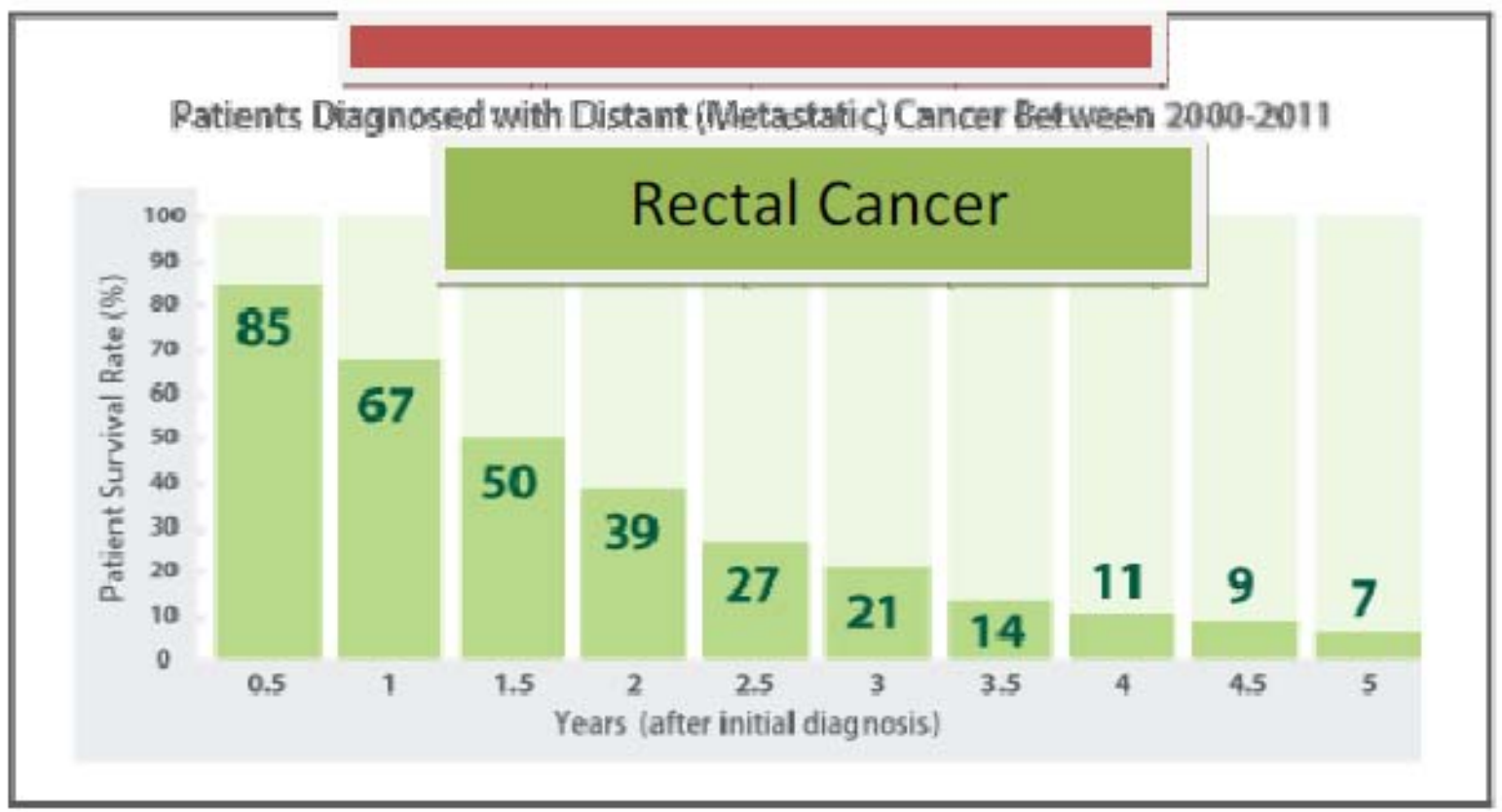

\section{Survival analysis}

At Cancer Treatment, it was understand that you may also wish to see the survival rates of the group of metastatic rectal cancer patients reported in the Surveillance, Epidemiology and End Results (SEER) database of the National Cancer Institute. SEER is a source of population-based information about cancer incidence and survival that includes the stage of cancer at the time of diagnosis and patient survival data. Collection of samples information on cancer incidence, prevalence and survival from specific geographic areas that represent $28 \%$ of the population in the world. It then makes these data available through its database at seer.cancer.gov.

Analyze of both the survival rates of the group of CTCA patients and the group of patients included in the SEER database.

The objective of this analysis was to see how long each group of patients survived after their diagnosis. The results are shown in the chart below. 


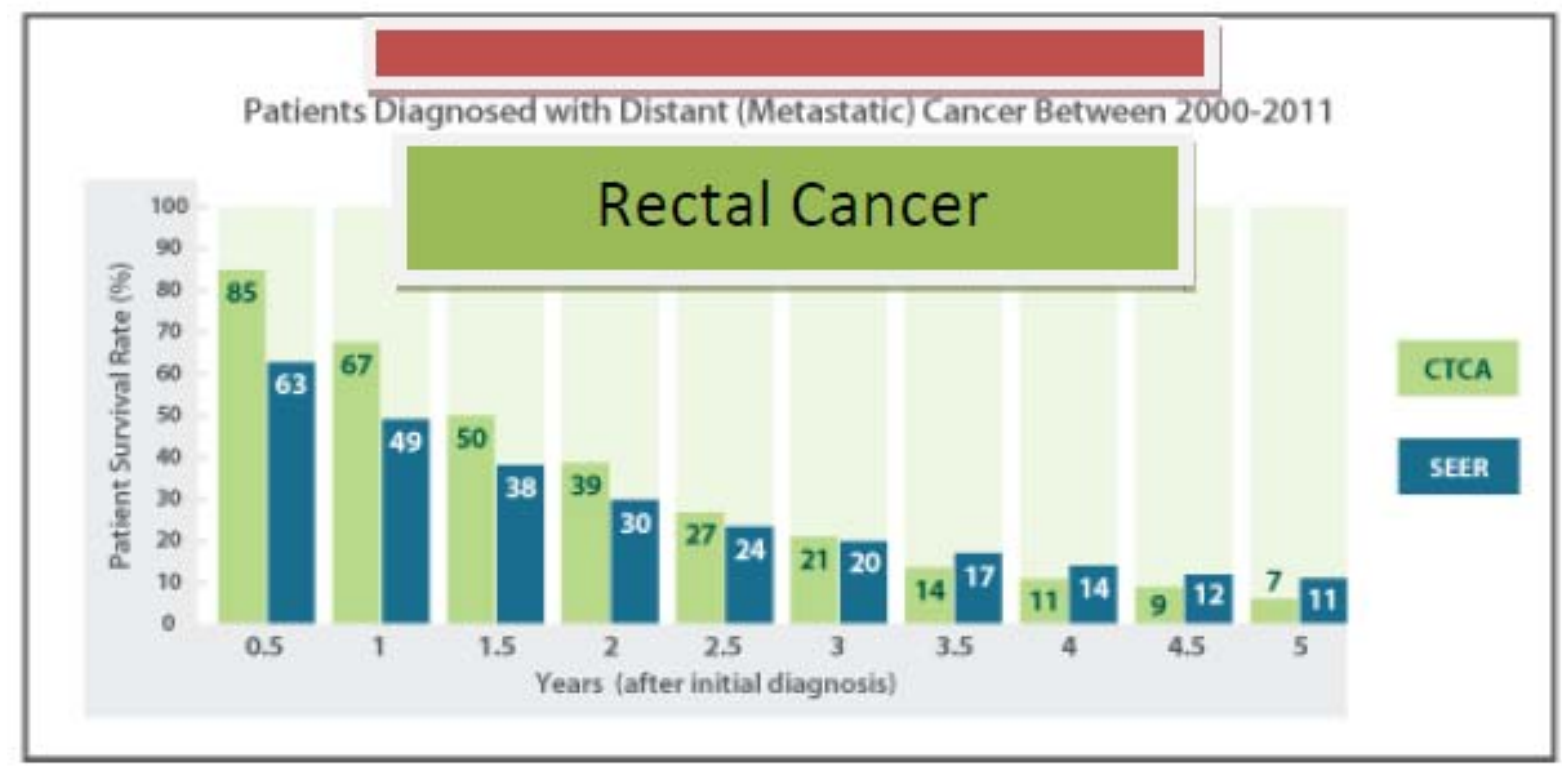

In the case of metastatic rectal cancer, 50\% of CTCA patients who were diagnosed between 2000 and 2011 and/or at least initially partly treated survived 1.5 years after the initial diagnosis, while 38\% of the SEER metastatic rectal cancer patients survived for at least that long.

\section{Conclusion}

A multidisciplinary approach that includes colorectal surgery, medical oncology, and radiation oncology is required for optimal treatment of patients with rectal cancer. Surgical technique, use of radiotherapy, and method of administering chemotherapy are important factors.

Strong considerations should be given to the intent of surgery, possible functional outcome, and preservation of anal continence and genitourinary functions. The first step involves achievement of cure, because the risk of pelvic recurrence is high in patients with rectal cancer, and locally recurrent rectal cancer has a poor prognosis.

Rectal cancer patients self-report their symptoms and quality of life interference issues using a symptom assessment tool that patients are invited to complete throughout their treatment. Findings from these assessments are used in creating personalized care plans.

\section{Acknowledgement}

I would like to express my sincere gratitude to all who have helped me in completion of my "CAPSTONE PROJECT". First of all I would like to express my gratitude to my Lecturers, the medical council of Nigeria and its Management for having given me a chance to do my CAPSTONE PROJECT at OAUTHC Ile-Ife, Osun State.

I am highly thankful for the kind support bestowed on me by the administration and staff of medical Laboratory Science etc.

My special thanks also goes to my dearly beloved Husband for his financial support given to me to complete this project.

Not living this behind, my special thanks goes to my creator, my potter and my strength, the Almighty God for giving me strength to write this project work.

\section{References}

[1]. Bullard KM, Rothenberger DA. Colon, rectum, and anus. Schwartz SE, ed. Principles of Surgery. 8th ed. New York, NY: McGraw Hill; 2005.

[2]. Baxter NN, Garcia-Aguilar J. Organ preservation for rectal cancer. J Clin Oncol. 2007 Mar 10. 25(8):1014-20. [Medline].

[3]. Brooks M. Local Excision for Rectal Cancer Increasing, but Inferior. Medscape Medical News. Available at http://www.medscape.com/viewarticle/815376. Accessed: December 23, 2013. 
[4]. Burn J, Gerdes AM, Macrae F, et al. Long-term effect of aspirin on cancer risk in carriers of hereditary colorectal cancer: an analysis from the CAPP2 randomised

[5]. Cao S, Bhattacharya A, Durrani FA, Fakih M. Irinotecan, oxaliplatin and raltitrexed for the treatment of advanced colorectal cancer. Expert Opinion on Pharmacotherapy. 2006. 7(6):687-703.

[6]. Current Therapy in Colon and Rectal Surgery. 2nd ed. Philadelphia, Pa: Mosby; 2005.

[7]. Ceelen WP, Van Nieuwenhove Y, Fierens K. Preoperative chemoradiation versus radiation alone for stage II and III resectable rectal cancer. Cochrane Database Syst Rev. 2009 Jan 21. CD006041. [Medline].

[8]. Colorectal Cancer: Systematic Review and Meta-analysis. Ann Intern Med. 2014. 160:171-181.

[9]. Ebert MP, Tanzer M, Balluff B, et al. TFAP2E-DKK4 and chemoresistance in colorectal cancer. $N$ Engl $J$ Med. 2012 Jan 5. 366(1):44-53. [Medline].

[10]. Giovannucci E, Wu K. Cancers of the colon and rectum. Schottenfeld D, Fraumeni J, eds. Cancer. Epidemiology and Prevention. 3rd ed. Oxford University Press; 2006.

[11]. Henderson D. Home-Based Stool Test Detects 79\% of Colorectal Cancers. Medscape Medical News. Available at http://www.medscape.com/viewarticle/820194. Accessed: February 10, 2014.

[12]. Hendlisz A, Van den Eynde M, Peeters M, Maleux G, Lambert B, Vannoote J, et al. Phase III trial comparing protracted intravenous fluorouracil infusion alone or with yttrium-90 resin microspheres radioembolization for liver-limited metastatic colorectal cancer refractory to standard chemotherapy. $J$ Clin Oncol. 2010 Aug 10. 28(23):3687-94. [Medline].

[13]. Hampel H. Genetic counseling in patients with familial risk for colorectal cancer. Presented at: NCCN 19th Annual Conference: Clinical Practice Guidelines \& Quality Cancer Care; March 13, 2014; Hollywood, Fla. [14]. J Natl Cancer Inst. 2001 Apr 18. 93(8):583-96. [Medline]. Schoen RE, Pinsky PF, Weissfeld JL, Yokochi LA, Church T, Laiyemo AO, et al. Colorectal-Cancer Incidence and Mortality.

[15]. Kapiteijn E, Marijnen CA, Nagtegaal ID, Putter H, Steup WH, Wiggers T. Preoperative radiotherapy combined with total mesorectal excision for resectable rectal cancer. N Engl J Med. 2001 Aug 30. 345(9):63846. [Medline].

[16]. Kumar A, Scholefield JH. Endosonography of the anal canal and rectum. World J Surg. 2000 Feb. 24(2):208-15. [Medline].

[17]. Kidwell KM, Yothers G, Ganz PA, Land SR, Ko CY, Cecchini RS, et al. Long-term neurotoxicity effects of oxaliplatin added to fluorouracil and leucovorin as adjuvant therapy for colon cancer: Results from National Surgical Adjuvant Breast and Bowel Project trials C-07 and LTS-01. Cancer. 2012 May 8. [Medline].

[18]. Lynch HT, de la Chapelle A. Hereditary colorectal cancer. N Engl J Med. 2003. 348:919â€"932.

[19]. Lipton LR, Johnson V, Cummings C, et al. Refining the Amsterdam Criteria and Bethesda Guidelines: testing algorithms for the prediction of mismatch repair mutation status in the familial cancer clinic. $J$ Clin Oncol. 2004 Dec 15. 22(24):4934-43. [Medline].

[20]. Lee JK, Liles EG, Bent S, Levin TR, Corley DA. Accuracy of Fecal Immunochemical Tests for

[21]. Mulcahy N. NCCN: Test all colorectal cancers for Lynch syndrome. Medscape Medical News. March 14, 2014. [Full Text].

[22]. Surveillance, Epidemiology, and End Results Program. SEER Stat Fact Sheets: Colon and Rectum Cancer. National Cancer Institute. Available at http://seer.cancer.gov/statfacts/html/colorect.html. Accessed: May 14, 2015.

[23]. Nelson H, Petrelli N, Carlin A, Couture J, Fleshman J, Guillem J, et al. Guidelines 2000 for colon and rectal cancer surgery.

[24]. Nielsen A, Munk C, Kjaer SK. Trends in incidence of anal cancer and high-grade anal intraepithelial neoplasia in Denmark, 1978-2008. Int J Cancer. 2012 Mar 1. 130(5):1168-73. [Medline].

[25]. Potter JD. Colorectal cancer: molecules and populations. J Natl Cancer Inst. 1999 Jun 2. 91(11):916-32. [Medline]. [Full Text].

[26]. Quan D, Gallinger S, Nhan C, Auer RA, Biagi JJ, Fletcher GG, et al. The role of liver resection for colorectal cancer metastases in an era of multimodality treatment: A systematic review. Surgery. 2012 Jun. 151(6):860-70. [Medline].

[27]. Robbins AS, Siegel RL, Jemal A. Racial disparities in stage-specific colorectal cancer mortality rates from 1985 to 2008.

[28]. Rothenberger D, Garcia-Aquilar J. Rectal cancer, local treatment. Current Therapy in Colon and Rectal Surgery. 2nd ed. Philadelphia, Pa: Mosby; 2005. 
Texila International Journal of Clinical Research

Volume 4, Issue 1, Dec 2016

[29]. Rothwell PM, Fowkes GR, Belch JF, Ogawa H, Warlow CP, Meade TW. Effect of daily aspirin on longterm risk of death due to cancer: analysis of individual patient data from randomized trials. Lancet. Dec 7/2010; Early online publication. [Full Text].

[30]. Simkens LH, Koopman M, Mol L, et al. Influence of body mass index on outcome in advanced colorectal cancer patients receiving chemotherapy with or without targeted therapy. Eur J Cancer. 2011 Nov. 47(17):25607. [Medline].

[31]. Stitzenberg KB, Sanoff HK, Penn DC, Meyers MO, Tepper JE. Practice patterns and long-term survival for early-stage rectal cancer. J Clin Oncol. 2013 Dec 1. 31(34):4276-82. [Medline]. [Full Text].

[32]. Weiser MR, Landmann RG, Wong WD, Shia J, Guillem JG, Temple LK, et al. Surgical salvage of recurrent rectal cancer after transanal excision. Dis Colon Rectum. 2005 Jun. 48(6):1169-75. [Medline]. van Helmond J, Beart RW. Cancer of the rectum: Operative management and adjuvant therapy. 